\section{HUMAN VOLUNTEER STUDIES INVESTIGATING THE POTENTIAL FOR TOXICOKINETIC INTERACTIONS BETWEEN THE PESTICIDES DELTAMETHRIN, PIRIMICARB AND CHLORPYRIFOS-METHYL FOLLOWING ORAL EXPOSURE AT THE ACCEPTABLE DAILY INTAKE}

Craig Sams, Kate Jones Health \& Safety Laboratory, Buxton, UK

10.1136/oemed-2011-100382.399

Objectives To determine whether there are metabolic interactions between deltamethrin or pirimicarb and chlorpyrifos-methyl in humans at dietary levels. Deltamethrin and pirimicarb are metabolised in-vivo by hydrolytic enzymes, which may be susceptible to inhibition by esterase-inhibiting compounds, such as chlorpyrifos-methyl.

Methods Human volunteer studies have been conducted by orally administering the pesticides deltamethrin $(0.01 \mathrm{mg} / \mathrm{kg} /$ day) or pirimicarb $(0.02 \mathrm{mg} / \mathrm{kg} /$ day $)$ at the acceptable daily intake (ADI) together with chlorpyrifos-methyl $(0.01 \mathrm{mg} / \mathrm{kg} /$ day), in order to investigate any potential interactions that may occur during dietary exposure. Urine samples were collected at time points up to at least $48 \mathrm{~h}$ post-exposure and metabolites were quantified. Urinary metabolite excretion data obtained from the mixed exposures were compared with data obtained from the same individuals given a dose of each individual pesticide on a separate occasion.

Results Metabolite excretion profiles for both pesticides administered as a mixed dose with chlorpyrifos-methyl were qualitatively similar to those obtained for the individual doses. Peak excretion of deltamethrin and pirimicarb metabolites occurred at around $4 \mathrm{~h}$ post-exposure for both the individual and the mixed exposure scenarios, and metabolite excretion was almost complete within $24 \mathrm{~h}$. No statistically significant differences were found between the individual and mixed doses for either metabolite excretion half-life or metabolite levels quantified in 24-h total urine collections.

Conclusions The data presented here indicate that no significant toxicokinetic interactions occur in humans between either deltamethrin or pirimicarb and chlorpyrifos-methyl when orally administered together at the ADI. 